\title{
Prevalence of Salmonella in poultry processing environments in wet markets in Penang and Perlis, Malaysia
}

\author{
Hafiz Nidaullah ${ }^{1}$, Nadarajan Abirami ${ }^{1}$, Ahamed Kamal Shamila-Syuhada ${ }^{1}$, Li-Oon Chuah ${ }^{1}$, Huda Nurul ${ }^{1}$,
} Teik Pei Tan², Farah Wahida Zainal Abidin² and Gulam Rusul ${ }^{1}$

1. Food Technology Division, School of Industrial Technology, Universiti Sains Malaysia, 11800 Minden, Penang, Malaysia;

2. Public Health Laboratory, Ministry of Health, Jalan Jelapang, 30020 Ipoh, Perak, Malaysia.

Corresponding author: Gulam Rusul, e-mail: rusulg@gmail.com,

Co-authors: HNidaullah: hafiz.nidaullah@gmail.com, NA: abirami0124@yahoo.com,

AKSS: shamila_syuhada@yahoo.com, LOC: nateliechuah@gmail.com, HNurul: nrlhd@usm.my, TPT: tanteikpei@moh.gov.my, FWZA: farahwahidaza@moh.gov.my

Received: 11-09-2016, Accepted: 20-01-2017, Published online: 06-03-2017

doi: 10.14202/vetworld.2017.286-292 How to cite this article: Nidaullah H, Abirami N, Shamila-Syuhada AK, Chuah LO, Nurul H, Tan TP, Zainal Abidin FW, Rusul G (2017) Prevalence of Salmonella in poultry processing environments in wet markets in Penang and Perlis, Malaysia, Veterinary World, 10(3): 286-292.

\begin{abstract}
Aim: The aim of this study was to determine the prevalence of various Salmonella serotypes in chickens, carcass contact surfaces as well as environmental samples collected from wet markets and small scale processing plant.

Materials and Methods: A total of 182 poultry and environmental samples were collected at random on separate occasions from wet markets and small scale processing plant, during the period of October 2014 to July 2015 in Penang and Perlis, Malaysia. The samples were analyzed for the presence of Salmonella using ISO 6579:2002 conventional culture-based method. Presumptive Salmonella colonies were subjected to various biochemical tests (such as triple sugar iron and lysine iron test), serologically confirmed using polyvalent $\mathrm{O}$ and $\mathrm{H}$ antisera and further serotyped at Public Health Laboratory, Ministry of Health, Perak, Malaysia.
\end{abstract}

Results: Salmonella serotypes were isolated from 161 out of 182 samples $(88.46 \%)$ with $100 \%$ prevalence in the whole chicken carcass and chicken cuts - as well as transport crate, cage, drum, knife, chopping board, display table, floor, bench wash water, wash water, and drain water. Salmonella was isolated from $91.67 \%, 83.33 \%$, and $66.67 \%$ of defeathering machines, drain swabs, and apron, respectively. 17 serotypes were isolated in this study with Salmonella Albany (57/161), Salmonella Corvallis (42/161), and Salmonella Brancaster (37/161) being the predominant serovars.

Conclusion: The most carcass contact and environmental samples collected along the wet market chicken processing line were consistently contaminated with Salmonella. This indicates that Salmonella has established itself in poultry processing environments by colonizing the surfaces of the equipment and survives in these environments by establishing biofilms. Our results highlight the need of implementing strict hygiene and sanitation standards to reduce the incidence of Salmonella. The prevalence of Salmonella in poultry can be reduced effectively by identifying and eliminating the sources and contamination sites during slaughter and processing of poultry.

Keywords: prevalence, poultry, Salmonella, wet markets.

\section{Introduction}

Salmonella is a leading cause of foodborne illness worldwide with an estimated annual economic loss of 3.7 billion dollars [1]. Although diseases due to this pathogen have been associated with a wide variety of food sources, poultry, in particular, have been regarded as the single largest cause of human salmonellosis [2]. In developing countries, such as Malaysia, poultry and poultry products are cheap and staple source of animal protein for all ethnic groups. Malaysia produces an estimate of 1.44 million tons of poultry meat and the consumption per capita are $40 \mathrm{~kg} /$ year, one of the highest in the world [3]. While

Copyright: Nidaullah, et al. Open Access. This article is distributed under the terms of the Creative Commons Attribution 4.0 International License (http://creativecommons.org/licenses/ by/4.0/), which permits unrestricted use, distribution, and reproduction in any medium, provided you give appropriate credit to the original author(s) and the source, provide a link to the Creative Commons license, and indicate if changes were made. The Creative Commons Public Domain Dedication waiver (http:// creativecommons.org/publicdomain/zero/1.0/) applies to the data made available in this article, unless otherwise stated. most poultry meat sold are processed in large-scale poultry processing facilities, wet markets still serve as an essential outlet for poultry distribution in Malaysia, accounting for $40 \%$ of total sales [3]. Wet markets are very common and popular in Asian countries. Wet markets serve as an avenue for retailing fresh produce, animal, and sea foods. The products are sold at ambient temperature and exposed to the environment. Ice is rarely used for chilling fresh produce or animal products, except for sea foods which are usually covered by ice. In most wet markets in Malaysia, the slaughter of poultry is not allowed or encouraged by local authorities but as Malaysians prefer freshly slaughtered poultry meat, thus poultry is slaughtered and retail in wet markets. The raw foods retailed at wet markets and floors of wet markets are constantly sprayed with water for washing and to maintain the humidity. As raw foods are exposed to the elements together with poor or inadequate hygienic measures in the local markets, we are of opinion there is a very high risk of Salmonella contamination of poultry sold 
in wet markets and should be of great concern to both the public and regulatory agencies.

The prevalence of various Salmonella serotypes among live birds ranges from $6 \%$ to $30 \%$ [4-7], while the incidence of Salmonella in poultry and poultry products ranges from $1 \%$ to $65.5 \%$ [8-13]. Infected live birds harbor and disseminate Salmonella to other birds via lateral transmission, mainly through feces, soil, litter, feeds, water, dust and feathers [14]. In addition, vertical or transovarian transmission of Salmonella occurs as eggs from colonized hens are used for the production of chicks. Chicks hatched from these eggs might excrete the bacterium, infecting other chicks [14]. As live birds are processed, the existing bacterium is introduced to poultry production system, and each stage of processing is a potential point for the environment for Salmonella contamination. Salmonella could, therefore, spread from carcass to carcass along the processing stages. In wet markets, the cross-contamination of Salmonella is further aggravated, due to poor hygiene and sanitation practices as well as the extensive amount of manual handling. Subsequently, Salmonella survives on chicken carcasses and other processed chicken products.

Understanding the contamination sources of Salmonella during slaughter and processing are imperative in reducing the prevalence of Salmonella in poultry. Numerous studies on the prevalence of Salmonella in poultry in Malaysia have been reported [15-17], but these studies focus on the occurrence of Salmonella rather than studying the source and dissemination mode of Salmonella. There is no information available to indicate whether the poultry is contaminated during processing in wet markets and small processing plants or during retailing, although studies have shown that live poultry is contaminated at the farm. Salmonella is present in the intestines, feathers, feet, and poor cleaning and sanitation will lead to cross-contamination and colonization of various sites in the wet markets and plants. The presence of high moisture in the environment of wet markets and poultry processing plants are ideal for the establishment and colonization by foodborne pathogens. Chmielewski and Frank [18] in an extensive review on biofilms and citing studies by other researchers observed that improperly cleaned surfaces promote biological soil build-up, and, in the presence of water, contribute to the development of bacterial biofilms which may contain pathogenic microorganisms. They also observed that Salmonella can easily attach and form biofilms on surfaces found in food processing plants, including plastic, cement, and stainless steel. According to our observation, poultry processing in wet markets and small scale processing plants in Malaysia involves constant rinsing steps as shown in Figure-1. Wet environment encountered in poultry processing plants is ideal for biofilm

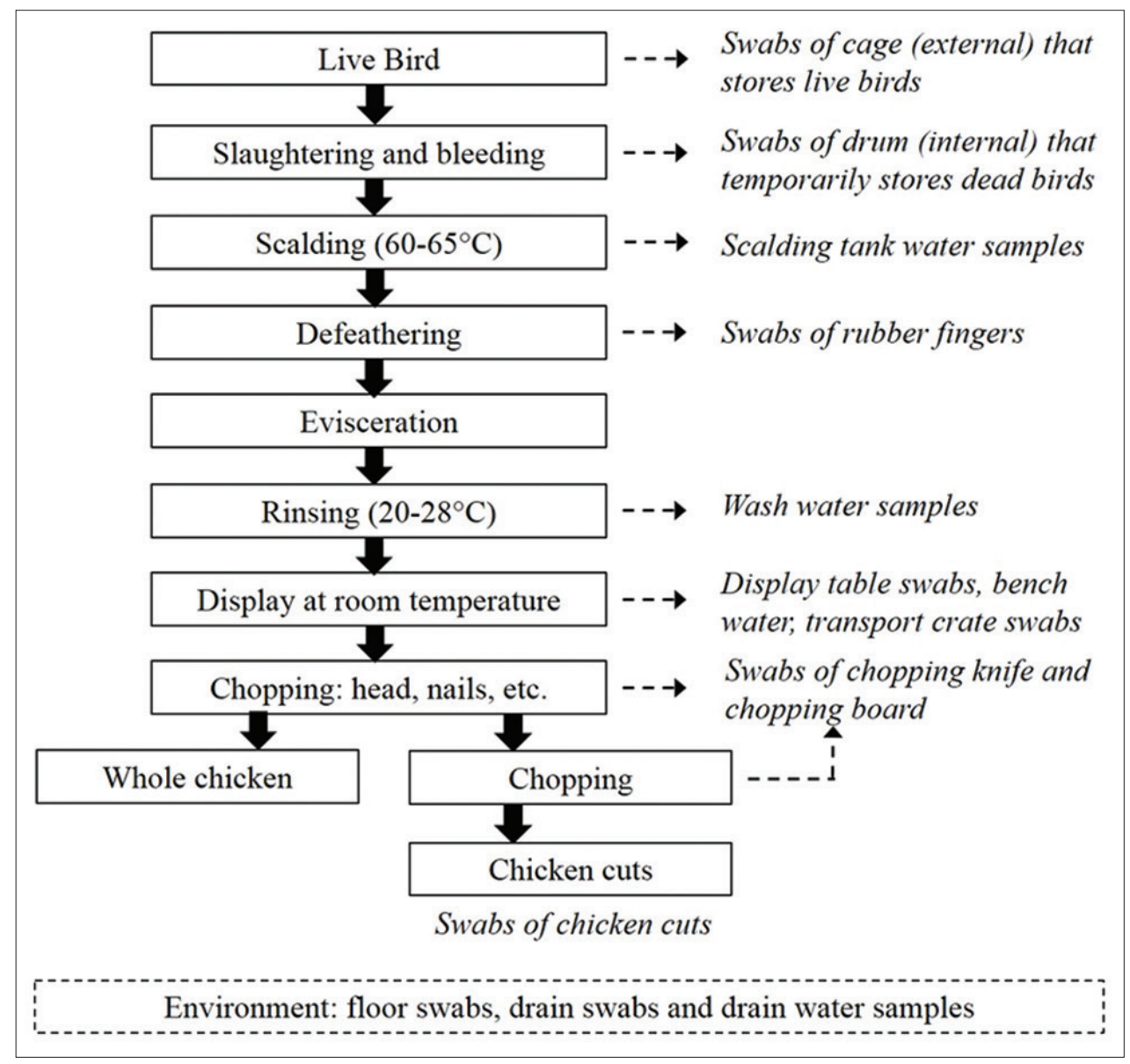

Figure-1: Flow diagram of poultry processing in wet markets with detailed description of Salmonella sampling points. 
formation. Studies have shown that Salmonella prevalent in poultry processing environment can be isolated from poultry processing equipment, especially in the slaughter and evisceration areas [19-21].

Arumugaswamy et al. [22] observed that 39\%, $35 \%$ and $44 \%$ of chicken parts, livers and gizzards were contaminated with Salmonella. Rusul et al. [15] reported that in Malaysia, the incidence of Salmonella in poultry carcasses obtained from wet markets and poultry processing plants ranged from $38.3 \%$ to $50 \%$. In a recent study, using the most probable number method in combination with multiplex polymerase chain reaction, Thung et al. [23] reported that the occurrence of Salmonella spp., Salmonella Enteritidis, and Salmonella Typhimurium in 120 chicken meat samples obtained from wet markets and hypermarkets was $20.80 \%, 6.70 \%$, and $2.50 \%$, respectively. Therefore, this study was undertaken to provide a detailed insight on the prevalence of Salmonella serotypes at different stages of poultry processing. The samples examined consisted of whole chicken carcasses, chicken cuts, and carcass contact surfaces such as utensils and processing equipment as well as environmental samples collected from wet markets and small scale processing plant located in Penang and Perlis.

\section{Materials and Methods}

\section{Ethical approval}

Live animals were not used in this study, hence ethical approval was not necessary. Poultry and environmental samples were collected from local wet markets and small scale processing plant.

\section{Sampling}

A total of 182 poultry (30/182) and environmental samples $(152 / 182)$ were collected at random on separate occasions from wet markets and small scale processing plant, during the period of October 2014 to July 2015 in Penang (108/180) and Perlis (74/180), Malaysia. Figure-1 shows the flow diagram of poultry processing in wet markets with a detailed indication of Salmonella sampling points. Environmental and process related samples - such as floor, display table, chopping board, knife, cage, drum, defeathering machine, transport crates, and drain crevices - were swabbed using $3 \mathrm{M}^{\mathrm{TM}}$ Sponge-Sticks (3M, USA) as per manufacturer's instructions. The swab-sampling method described by Gill et al. [24] was adopted for the whole chicken carcass and chicken cuts. Scalding tank water, wash water (water used for washing carcass after defeathering), bench wash water (stagnant fluids on display table), and drain water samples were collected in sterile Schott bottles $(100 \mathrm{ml})$. All samples were transported in a polystyrene box containing ice and analyzed immediately on reaching the lab.

\section{Culture-based method}

Enumeration and isolation of Salmonella in poultry and its related process and environmental samples was carried out according to ISO 6579:2002 Horizontal
Method [25], with slight modification. Processing and environmental swab samples ( $25 \mathrm{~g})$ were pre-enriched in $225 \mathrm{ml}$ of buffered peptone water (BPW) (3M, USA). Water samples $(25 \mathrm{ml})$ were pre-enriched in $225 \mathrm{ml}$ of BPW as well. Both test (swab and water) samples were incubated at $37 \pm 1^{\circ} \mathrm{C}$ for $24 \pm 2 \mathrm{~h}$. Upon pre-enrichment, $0.1 \mathrm{ml}$ aliquot of test samples were transferred into $9.9 \mathrm{ml}$ of rappaport vassiliadis soya (RVS) broth and were incubated at $42 \pm 1{ }^{\circ} \mathrm{C}$ (RVS) for $24 \pm 2 \mathrm{~h}$. Concurrently, $1 \mathrm{ml}$ aliquot of pre-enriched test samples was transferred into $9 \mathrm{ml}$ Muller-Kauffmann tetrathionate-novobiocin (MKTTn) broth and was incubated at $37 \pm 1^{\circ} \mathrm{C}$ (MKTTn) for $24 \pm 2 \mathrm{~h}$. One loop of RVS and MKTTn were streaked onto following selective agars: Xylose lysine deoxycholate agar, rambach agar, xylose lysine tergitol-4 agar, and hektoen enteric agar. The selectice agar plates were then incubated at $37 \pm 1^{\circ} \mathrm{C}$ for $24 \pm 2 \mathrm{~h}$. Presumptive Salmonella colonies were chosen and purified and subjected to the biochemical tests such as triple sugar iron and lysine iron test. Media used for selective enrichment, selective plating, purification, and biochemical tests were purchased from Merck, Germany. Salmonella isolates were also serologically confirmed by using polyvalent $\mathrm{O}$ and $\mathrm{H}$ antisera (BD Franklin Lakes, USA). The Salmonella isolates were serotyped at Public Health Laboratory, Perak, Ministry of Health Malaysia.

\section{Results}

Salmonella was isolated from 161 out of 182 samples $(88.46 \%)$. All chicken carcasses (15/15) and chicken cuts/portions (15/15) were positive for Salmonella (Table-1). Salmonella was also isolated

Table-1: Detection of Salmonella in various samples obtained from wet markets and small scale processing plant located in Penang and Perlis.

\begin{tabular}{|c|c|c|c|}
\hline $\begin{array}{l}\text { Samples } \\
\text { tested }\end{array}$ & $\begin{array}{c}\text { Number of } \\
\text { samples } \\
\text { tested }\end{array}$ & $\begin{array}{c}\text { Number } \\
\text { of positive } \\
\text { samples }\end{array}$ & Prevalence (\%) \\
\hline Cage & 11 & 11 & 100.00 \\
\hline Drum & 12 & 12 & 100.00 \\
\hline $\begin{array}{l}\text { Scalding } \\
\text { tank water }\end{array}$ & 17 & 0 & 0.00 \\
\hline $\begin{array}{l}\text { Defeathering } \\
\text { machine }\end{array}$ & 12 & 11 & 91.67 \\
\hline Wash water & 8 & 8 & 100.00 \\
\hline $\begin{array}{l}\text { Chopping } \\
\text { board }\end{array}$ & 17 & 17 & 100.00 \\
\hline $\begin{array}{l}\text { Whole } \\
\text { chicken }\end{array}$ & 15 & 15 & 100.00 \\
\hline Chicken cuts & 15 & 15 & 100.00 \\
\hline Knife & 14 & 14 & 100.00 \\
\hline Display table & 17 & 17 & 100.00 \\
\hline Floor & 17 & 17 & 100.00 \\
\hline Drain swab & 6 & 5 & 83.33 \\
\hline Drain water & 9 & 9 & 100.00 \\
\hline Crates & 4 & 4 & 100.00 \\
\hline $\begin{array}{l}\text { Bench wash } \\
\text { water }\end{array}$ & 2 & 2 & 100.00 \\
\hline Apron & 6 & 4 & 66.67 \\
\hline Overall & 182 & 161 & 88.46 \\
\hline
\end{tabular}


from all environmental samples (floor, bench wash water, wash water and drain water) and contact surface of equipment (transport crate, cage, drum, knife, chopping board, and display table). Salmonella was detected in $91.67 \%(11 / 12), 83.33 \%(5 / 6)$, and $66.67 \%(4 / 6)$ defeathering machines, drain, and apron swabs, respectively (Table-1). All (0/17) scalding tank water samples were negative for Salmonella. Results in Table-2 show that the incidence of Salmonella was very high in wet markets located in Penang (83.3391.67\%) and Perlis (80.00-92.86\%). This suggests

Table-2: Incidence of Salmonella at different wet markets and small scale processing plant in Penang and Perlis.

\begin{tabular}{|c|c|c|c|c|}
\hline Location & Visit & $\begin{array}{c}\text { Number } \\
\text { of positive } \\
\text { sample }\end{array}$ & $\begin{array}{c}\text { Total } \\
\text { number } \\
\text { of sample }\end{array}$ & Prevalence (\%) \\
\hline \multicolumn{5}{|l|}{ Penang } \\
\hline \multirow[t]{4}{*}{ Jelutonga } & 1 & 10 & 11 & 90.91 \\
\hline & 2 & 10 & 11 & 90.91 \\
\hline & 3 & 10 & 11 & 90.91 \\
\hline & 4 & 10 & 11 & 90.91 \\
\hline Batu & 1 & 10 & 12 & 83.33 \\
\hline \multirow[t]{2}{*}{ Lancanga } & 2 & 10 & 12 & 83.33 \\
\hline & 3 & 11 & 12 & 91.67 \\
\hline \multirow[t]{3}{*}{ Lip $\operatorname{Sin}^{a}$} & 1 & 5 & 6 & 83.33 \\
\hline & 2 & 5 & 6 & 83.33 \\
\hline & 3 & 5 & 6 & 83.33 \\
\hline \multicolumn{4}{|l|}{ Sardon ${ }^{a}$} & 90.00 \\
\hline $\begin{array}{l}\text { Grand } \\
\text { total }\end{array}$ & & 95 & 108 & 87.96 \\
\hline \multicolumn{5}{|l|}{ Perlis } \\
\hline \multirow[t]{2}{*}{ Pauha $^{a}$} & 1 & 12 & 14 & 85.71 \\
\hline & 2 & 13 & 14 & 92.86 \\
\hline Mata & 1 & 12 & 13 & 92.31 \\
\hline Ayer ${ }^{a}$ & 2 & 12 & 13 & 92.31 \\
\hline \multirow[t]{2}{*}{$\mathrm{SSPC}^{\mathrm{b}}$} & 1 & 8 & 10 & 80.00 \\
\hline & 2 & 9 & 10 & 90.00 \\
\hline $\begin{array}{l}\text { Grand } \\
\text { total }\end{array}$ & & 66 & 74 & 89.19 \\
\hline
\end{tabular}

aWet markets, bSmall scale processing plant that Salmonella is persistent in the environment of wet markets of both states, indicating colonization and survival in biofilms.

Seventeen different Salmonella serovars were isolated from samples obtain from wet markets and small-scale processing plants located in Penang and Perlis. The various Salmonella serovars isolated and their distribution is presented in Table-3. The predominant serovars isolated were Salmonella Albany (57/161), Salmonella Corvallis (42/161), and Salmonella Brancaster (37/161). Salmonella Enteritidis (5/161), Salmonella Typhimurium (4/161), Salmonella Florian (3/161), and Salmonella Braenderup (3/161) were also detected. The prevalence of other serovars such as Salmonella Give, Salmonella Weltevreden, Salmonella Kivu, Salmonella Sarajane, Salmonella Haifa, Salmonella Indiana, Salmonella Kentucky, Salmonella Oyonnax, Salmonella Chester, and Salmonella Stanley was very low $(<2)$. Among the 17 different Salmonella serovars, nine different serovars were isolated from wet markets in Penang, and the predominant serovars were $S$. Corvallis (34/95), $S$. Albany (28/95), and $S$. Brancaster (21/95). 14 different Salmonella serovars were isolated from wet markets, and small-scale processing plant in Perlis and the most predominant serovars were $S$. Albany (29/66), $S$. Brancaster (16/66), and $S$. Corvallis $(8 / 66)$.

\section{Discussion}

A recent Salmonella outbreak in Kedah, Malaysia which resulted in four deaths and 38 cases of hospitalization due to inappropriate storage of raw chicken, followed by insufficient cooking and the subsequent consumption of contaminated chicken dish [26] has underlined the implication of Salmonella contamination in poultry. In this study, poultry, poultry contact surfaces of equipment used in poultry processing and environmental samples from wet markets and small

Table-3: Salmonella serovars isolated from different wet markets and small scale processing plant located in Penang and Perlis.

\begin{tabular}{|c|c|c|c|c|c|c|c|c|}
\hline \multirow[t]{2}{*}{ Salmonella serovars } & \multicolumn{4}{|c|}{ Penang } & \multicolumn{3}{|c|}{ Perlis } & \multirow{2}{*}{$\begin{array}{c}\text { Number of isolates } \\
\text { ( } \% \text { prevalence) }\end{array}$} \\
\hline & Jelutong & Batu Lancang & Lip Sin & Tun Sardon & Pauh & Mata Ayer & SSPC & \\
\hline Salmonella Albany & 13 & 11 & 1 & 3 & 9 & 16 & 4 & $57(35.40)$ \\
\hline Salmonella Corvalis & 19 & 7 & 6 & 2 & 4 & 1 & 3 & $42(26.09)$ \\
\hline Salmonella Brancaster & 2 & 13 & 5 & 1 & 10 & 4 & 2 & $37(22.98)$ \\
\hline Salmonella Enteritidis & 2 & & 2 & & & 1 & & $5(3.11)$ \\
\hline Salmonella Typhimurium & 2 & & 1 & & 1 & & & $4(2.48)$ \\
\hline Salmonella Florian & & & & & 1 & 2 & & $3(1.86)$ \\
\hline Salmonella Braenderup & & & & 2 & & & 1 & $3(1.86)$ \\
\hline Salmonella Give & 1 & & & & & & & $1(0.62)$ \\
\hline Salmonella Weltevreden & & & & & & & 1 & $1(0.62)$ \\
\hline Salmonella Kivu & & & & & & & 1 & $1(0.62)$ \\
\hline Salmonella Sarjane & & & & & & & 1 & $1(0.62)$ \\
\hline Salmonella Haifa & 1 & & & & & & & $1(0.62)$ \\
\hline Salmonella Indiana & & & & 1 & & & & $1(0.62)$ \\
\hline Salmonella Kentucky & & & & & & & 1 & $1(0.62)$ \\
\hline Salmonella Oyonnax & & & & & & & 1 & $1(0.62)$ \\
\hline Salmonella Chester & & & & & & & 1 & $1(0.62)$ \\
\hline Salmonella Stanley & & & & & & & 1 & $1(0.62)$ \\
\hline Overall & 40 & 31 & 15 & 9 & 25 & 24 & 17 & $161(100.00)$ \\
\hline
\end{tabular}


scale processing plant were analyzed for the presence of Salmonella.

Our study demonstrated a high occurrence $(88.46 \%)$ of Salmonella in poultry, contact surfaces used in poultry processing and environmental samples obtained from wet markets and small scale processing plant. Chicken carcass, chicken cuts/portions, contact surfaces (transport crate, cage, drum, knife, chopping board, and display table), and environmental samples (bench wash water, wash water and drain water and floor) were all positive for Salmonella. Arumugaswamy et al. [22] reported that the prevalence of Salmonella in chicken pieces, livers, and gizzards sampled from retail outlets were 39.4\% (13/33), 35.3\% (6/17), and 44.4\% (8/18), respectively. Similarly, Rusul et al. [15] reported 35.5\% (158/445) and $50.0 \%(52 / 104)$ broiler carcasses obtained from wet markets and processing plants, respectively, were contaminated with Salmonella. However, in a recent study, Modarressi and Thong [16] reported a high prevalence of Salmonella (72.7\%) in chicken meats sampled during 2006-2009 in Kuala Lumpur. Other researchers [8-13] have reported that the incidence of Salmonella to be much lower (1-65.5\%) compared to findings of Moderressi and Thong [16]. The major difference between this study and the previous studies could be due to sampling strategy and geographical area. In this study, samples were obtained at the various stages of processing (from slaughter to retailing at the wet markets). In this study, environmental and contact surfaces were also examined to determine the potential for cross-contamination. Thus, the focus of this study was to determine the contamination sites and to trek the dissemination of Salmonella during slaughtering and processing. Besides reporting a high prevalence of Salmonella in poultry and their processing environments, our results also suggested that frequent contamination of Salmonella occurs along the processing line. The previous studies as reported by other researchers only focused on the prevalence of Salmonella in chicken carcasses or chicken cuts and chicken by-products such as organs (gizzards, livers, and intestines). This could explain the low prevalence of Salmonella compared to our study which focused on the prevalence of Salmonella at different stages of processing in wet markets. In our opinion, the high incidence of Salmonella in samples obtained from wet markets is due to cross contamination. The prevalence of Salmonella in live birds arriving in wet markets might be very low but during processing under unhygienic conditions led to the amplification of contamination of the carcass from various stages along the processing continuum.

The predominant serovars detected in samples obtained from wet markets in Penang and Perlis were $S$. Albany, $S$. Corvallis, and $S$. Brancaster. However, the pattern of predominance was different as $S$. Albany was the predominant serovar in Perlis, followed by $S$. Brancaster and $S$. Corvallis; while in Penang, the predominant serovar was $S$. Corvallis, followed by $S$. Albany and $S$. Brancaster. The serovars isolated in this study were different from those reported by Rusul et al. [15]. In their study, Rusul et al. [15] isolated 14 serovars from carcass obtained from wet market, with $S$. Muenchen (32.6\%), S. Enteritidis (19.8\%), $S$. Kentucky (17\%), and $S$. Blockley (12.8\%) as the predominant serovars. In another study, Arumugaswamy et al. [22] isolated eight serovars from poultry and giblets, with $S$. Blockley, $S$. Enteritidis, and $S$. Chincol as the most predominant serovars. Two similar studies conducted in Thailand showed that the predominant serovars in Thailand were $S$. Corvallis, $S$. Albany, $S$. Enteritidis, and $S$. Virchow [27], while Chotinun et al. [28] reported that $S$. Corvallis, Salmonella Rissen, Salmonella Hadar, S. Enteritidis, S. Stanley, and $S$. Weltevreden were the predominant serovars. Bae et al. [29], on the other hand, reported $S$. Enteritidis, Salmonella Montevideo and Salmonella Senftenberg as the most prevalent serovars isolated from poultry slaughterhouses in Korea. In general, the distribution of Salmonella serovars varies over time, different geographical locations, production scale and the country's development status [30]. Type of serovars and their distribution pattern is almost constant in developed countries while it varies greatly with time in developing countries [30]. Some serovars remain dominant over many years, others emerge, re-emerge or decrease over time [31]. Moreover, a rapid international trade in food and agricultural products has eased the interpolation of Salmonella serovars across the geographic boundaries of importing countries [32].

It is worth to note that the prevalence of Salmonella has considerably increased over the years in Malaysia, suggesting that poultry from wet markets can be an important vehicle for the transmission Salmonella spp. This may be attributed to increased poultry production and the stress induced during poultry transportation [22], while in wet markets, the high prevalence of Salmonella can be attributed to poor hygiene and sanitation practices. The incidence of Salmonella in poultry at the farm level might be low but during transportation in overcrowded cages over a long distance will lead to stress among the poultry. It is a well-known fact there is an increase in shedding of Salmonella or other enteric pathogens if live poultry or life animals are subject to stress especially during transportation [33,34]. Heyndrickx et al. [34] in an epidemiological study on the dissemination of Salmonella from hatchery to slaughterhouse observed a significant increase in Salmonella contamination during transport. Poultry birds can be colonized by Salmonella via vertical and lateral transmission (environment) route [14]. The live birds are loaded and transported to wet market in plastic cages, and during transportation period, the cages may get contaminated by feces, litters and feathers. In this study, all the cage samples were positive for Salmonella, indicating that the cage used to transport live birds can be a source 
of contamination. The impact of unclean and recycled transport crate for live bird transportation have been well documented [35].

Many studies have shown that cross-contamination of poultry can occur during processing. In the processing plants and wet markets, the sources of contamination can be workers, equipment such as defeathering machines, scalding water and tanks, chilling tanks, floors, drains work benches, and knives. Salmonella serovars can also survive for a long time in biofilms which are formed on surfaces, and these biofilms tend to protect Salmonella from detergents and sanitizers. In wet markets, the live birds are killed, scalded in hot water, plucked and eviscerated, mostly by hand. Extensive human handling involved, at each stage of processing, contributes to cross-contamination. In this study, it was found that most carcass contact and environmental samples collected along chicken processing line were consistently contaminated with Salmonella. All scalding tank samples were negative for Salmonella. The scalding process involves immersing the carcass in hot water at $50-58^{\circ} \mathrm{C}$ for $4 \mathrm{~min}$, to loosen the feathers from skin pores, which facilitates the defeathering process [36]. Due to the high temperature employed during scalding, Salmonella was not isolated from the scalding water samples. After scalding, the carcasses are subjected to defeathering and evisceration. Both processes are of major concerns in poultry industry as it may lead to cross contamination and recontamination of carcasses [37]. The rubber fingers in defeathering machine harbor pathogens, which in turn contaminates the carcass while careless harvesting of entrails and intestines manually could contaminate the carcass during evisceration as a result of intestinal content spillage [37]. After defeathering, the carcasses are rinsed with water. In this study, all the wash water samples were positive for Salmonella. In wet markets, where Salmonella was isolated from wash water, suggests limited water supply and the water used for rinsing of carcass is recycled frequently. The presence of Salmonella on chopping board, knife and display table suggest this pathogen have colonized these contact surfaces through formation of biofilms and thus able to survive cleaning. We observed there are no systematic cleaning or sanitation programs in the wet markets. The cleaning is carried out by hosing of loose soils such as dirt, blood, feather and tissue residues. We also observed potholes, puddles of water and the drain walls are covered with algae and due to poor gradient water flow is slow.

\section{Conclusions}

This study describes the prevalence of Salmonella contamination in the whole chicken carcass, cut chickens, processing and environmental samples obtained from wet market and small-scale processing plant in Perlis and Penang, Malaysia. The study found contamination of Salmonella in whole and cut chickens, utensils and equipment used in processing, in wash, scalding tank, bench and drain water and floor around the wet markets and small scale processing plant, indicating potential sources and routes of the Salmonella transmission in poultry, as well as its processing environment. Predominant Salmonella serotypes isolated were $S$. Albany, $S$. Corvallis and $S$. Brancaster. The relatively high prevalence in chickens and its processing environment in local wet markets and small scale processing plant indicates that poultry is undoubtedly a major potential source of human salmonellosis. These results call for urgent attention as such prevalence are imminent risk to public health. This research also highlights the need of implementing a stricter hygiene and sanitation standard in local wet markets and small scale processing plant to reduce the incidence of Salmonella. As poultry processing involved multiple stages, there is evidence that some of the processing steps facilitate the contamination of poultry carcasses.

\section{Authors' Contributions}

GR conceived and designed the study. HNidaullah and NA carried out sampling and laboratory analysis. AKSS, LOC and HNurul analyzed and interpreted the data. TPT and FWZA assisted with the serovar typing. All authors wrote, revised and approved the manuscript.

\section{Acknowledgments}

The work was supported by Research University Grant Scheme (1001/PTEKIND/811289) of Ministry of Higher Education, Malaysia.

\section{Competing Interests}

The authors declare that they have no competing interests.

\section{References}

1. USDA (United States Department of Agriculture). (2015) Economic Research Service. Available from: http://www. ers.usda.gov/data-products/chart-gallery/detail.aspx?char$\mathrm{tId}=50500$. Accessed on 25-04-2016.

2. Gould, L.H., Walsh, K.A., Vieira, A.R., Herman, K., Williams, I.T., Hall, A.J. and Cole, D. (2013) Surveillance for foodborne disease outbreaks - United States, 1998-2008. Morb. Mortal. Wkly. Rep., 62: 1-34.

3. Wahab, A.G. and Rittgers, C. (2014) Broiler Meat Sector, Malaysia. USDA Foreign Agricultural Service. Available from: http://www.thefarmsite.com/reports/contents/MalaysiaPoultry14March2014.pdf. Accessed on 02-02-2016.

4. Liljebjelke, K.A., Hofacre, C.L., Liu, T., White, D.G., Ayers, S., Young, S. and Maurer, J.J. (2005) Vertical and horizontal transmission of Salmonella within integrated broiler production system. Foodborne Pathog. Dis., 2: 90-102.

5. van de Giessen, A.W., Bouwknegt, M., Dam-Deisz, W.D.C., van Pelt, W., Wannet, W.J. and Visser, G. (2006) Surveillance of Salmonella spp. and Campylobacter spp. In poultry production flocks in the Netherlands. Epidemiol. Infect., 134: 1266-1275.

6. Gutierrez, M., Fanning, J., Murphy, A., Murray, G., Griffin, M., Flack, A., Leonard, N. and Egan, J. (2009) Salmonella in broiler flocks in the republic of Ireland. 
Foodborne Pathog. Dis., 6: 111-120.

7. Srinivasan, P., Balasubramaniam, G.A., Murthy, T.R.G., Saravanan, S. and Balachandran, P. (2014) Prevalence and pathology of salmonellosis in commercial layer chicken from Namakkal, India. Pak. Vet. J., 34(3): 324-328.

8. Antunes, P., Réu, C., Sousa, J.C., Peixe, L. and Pestana, N. (2003) Incidence of Salmonella from poultry products and their susceptibility to antimicrobial agents. Int. J. Food Microbiol., 82: 97-103.

9. Jordan, E., Egan, J., Dullea, C., Ward, J., McGillicuddy, K., Murray, G., Murphy, A., Bradshaw, B., Leonard, N., Rafter, P. and McDowell, S. (2006) Salmonella surveillance in raw and cooked meat and meat products in the Republic of Ireland from 2002 to 2004. Int. J. Food Microbiol., 112: 66-70.

10. Fearnley, E., Raupach, J., Lagala, F. and Cameron, S. (2011) Salmonella in chicken meat, eggs and humans; Adelaide, South Australia, 2008. Int. J. Food Microbiol., 146: 219-227.

11. Hue, O., Le Bouquin, S., Lalande, F., Allain, V., Rouxel, S., Petetinb, I., Quesnea, S., Laisneya, M.J., Gloaguena, P.Y., Picherotd, M., Salvata, G., Bougeardc, S. and Chemalya, M. (2011) Prevalence of Salmonella spp. On broiler chicken carcasses and risk factors at the slaughterhouse in France in 2008. Food Control, 22: 1158-1164

12. Hyeon, J.Y., Chon, J.W., Hwang, I.G., Kwak, H.S., Kim, M.S., Kim, S.K., Choi, I.S., Song, C.S., Park, C. and Seo, K.H. (2011) Prevalence, antibiotic resistance, and molecular characterization of Salmonella serovars in retail meat products. J. Food Prot., 74: 161-166.

13. Yang, B., Xi, M., Wang, X., Cui, S., Yue, T., Hao, H., Wang, Y., Cui, Y., Alali, W.Q., Meng, J., Walls, I., Wong, D.M. and Doyle, M.P. (2011) Prevalence of Salmonella on raw poultry at retail markets in China. J. Food Prot., 74: 1724-1728.

14. Hamilton, E. (2000) Salmonella enteritidis and Salmonella typhimurium. Poultry Industry Council, Factsheet \# 105. Available from: http://www.poultryindustrycouncil.ca.pdfs/ factsheets/fs_105.pdf. Accessed on 25-03-2016.

15. Rusul, G., Khair, J., Radu, S. and Yassin, R. (1996) Prevalence of Salmonella in broilers at retail outlets, processing plants and farms in Malaysia. Int. J. Food Microbiol., 33: 183-194.

16. Modarressi, S. and Thong, K.L. (2010) Isolation and molecular sub typing of Salmonella enterica from chicken, beef and street foods in Malaysia. Sci. Res. Essays, 5: 2713-2720.

17. Adzitey, F., Rusul, G. and Huda, N. (2012) Prevalence and antibiotic resistance of Salmonella serovars in ducks, duck rearing and processing environments in Penang, Malaysia. Food Res. Int., 45: 947-952.

18. Chmielewski, R.A.N. and Frank, J.F. (2003) Biofilm formation and control in food processing facilities. Compr. Rev. Food Sci. Food Saf., 2: 22-32.

19. Helke, D.M., Somers, E.B. and Wong, A.C.L. (1993) Attachment of Listeria monocytogenese and Salmonella typhimurium to stainless steel and buna-N in the presence of milk and individual milk components. J. Food Prot., 56(6): 479-484.

20. Helke, D.M. and Wong, A.C.L. (1994) Survival and growth characteristics of Listeria monocytogenes and Salmonella typhimurium on stainless steel and buna-N rubber. J. Food Prot., 57(11): 963-968.

21. Joseph, B., Otta, S.K., Karunasagar, I. and Karunasagar, I. (2001) Biofilm formation by Salmonella spp. On food contact surfaces and their sensitivity to sanitizers. Int. J. Food Microbiol., 64(3): 367-372.

22. Arumugaswamy, R.K., Rusul, G., Hamid, S.N.A. and Cheah, C.T. (1995) Prevalence of Salmonella in raw and cooked foods in Malaysia. Food Microbiol., 12: 3-8.
23. Thung, T.Y., Mahyudin, N.A., Basri, D.F., Wan Mohamed Radzi, C.W.J., Nakaguchi, Y., Nishibuchi, M. and Radu, S. (2016) Prevalence and antibiotic resistance of Salmonella Enteritidis and Salmonella Typhimurium in raw chicken meat at retail markets in Malaysia. Poult. Sci., 95(8): 1888-1893.

24. Gill, C.O., Badoni, M., Moza, L.F., Barbut, S. and Griffiths, M.W. (2005) Microbiological sampling of poultry carcass portions by excision, rinsing, or swabbing. J. Food Prot., 68: 2718-2720.

25. ISO. (2002) ISO 6579 Microbiology of Food and Animal Feeding Stuffs: Horizontal Method for the Detection of Salmonella spp. ISO, Geneva, Switzerland.

26. ProMed Mail. (2013) Salmonellosis - Malaysia: (Kedah), Wedding Banquet, Fatal International Society for Infectious Diseases. Available from: http://www.promedmail.org/direct.php?id=20131008.1989195. Accessed on 25-04-2015.

27. Lampang, K.N., Chailangkarn, S. and Padungtod, P. (2013) Prevalence and antimicrobial resistance of Salmonella serovars in chicken farm, Chiang Mai and Lamphun province, Northern of Thailand. Chiang Mais Vet. Subst., 12: 85-93.

28. Chotinun, S., Rojanasthien, S., Unger, F., Tadee, P. and Patchanee, P. (2015) Prevalence and antimicrobial resistance of Salmonella isolated from carcasses, processing facilities and the environment surrounding small scale poultry slaughterhouses in Thailand. Southeast Asian J. Trop. Med., 45: 1392-1400.

29. Bae, D.H., Dessie, H.K., Baek, H.J., Kim, S.G., Lee, H.S. and Lee, Y.J. (2013) Prevalence and characteristics of Salmonella spp. isolated from poultry slaughterhouses in Korea. J. Vet. Med. Sci., 75: 1193-1200.

30. Hendriksen, R.S., Vieira,A.R., Karlsmose, S., Wong, D.M.L., Jensen, A.B., Wegener, H.C. and Aarestrup, F.M. (2011) Global monitoring of Salmonella serovar distribution from the World Health Organization global foodborne infections network country data bank: Results of quality assured laboratories from 2001 to 2007. Foodborne Pathog. Dis., 8: 887-900

31. Molla, B., Alemayehu, D. and Salah, W. (2003) Sources and distribution of Salmonella serotypes isolated from food animals, slaughterhouse personnel and retail meat products in Ethiopia: 1997-2002. Ethiop. J. Health Dev., 17: 63-70.

32. D'Aoust, J.Y. (1994) Salmonella and the International Food Trade. Int. J. Food Microbiol., 24: 11-31.

33. Marin, C. and Lainez, M. (1990) Salmonella detection in feces during broiler rearing and after live transport to the slaughterhouse. Am. J. Vet. Res., 51(6): 866-869.

34. Heyndrickx, M., Vandekerchove, D., Herman, L., Rollier, I., Grijspeerdt, K. and De Zutter, L. (2002) Routes for Salmonella contamination of poultry meat: Epidemiological study from hatchery to slaughterhouse. Epidemiol. Infect., 129: 253-265.

35. Slader, J., Domingue, G., Jørgensen, F., McAlpine, K., Owen, R.J., Bolton, F.J. and Humphrey, T.J. (2002) Impact of transport crate reuse and of catching and processing on Campylobacter and Salmonella contamination of broiler chickens. Appl. Environ. Microbiol., 68: 713-719.

36. Finstad, S., O'Bryan, C.A., Marcy, J.A., Crandall, P.G. and Ricke, S.C. (2012) Salmonella and broiler processing in the United States: Relationship to foodborne salmonellosis. Food Res. Int., 45: 789-794

37. da Silva, M.V. (2009) Poultry and Poultry Products - Risks for Human Health (Slaughtering and Processing). Food and Agriculture Organization of the United Nations Poultry Development Review. Available from: http://www.fao.org/ docrep/013/al742e/al742e00.pdf. Accessed on 25-03-2016. 